\title{
Sero-prevalence of SARS CoV-2 specific antibody among general population of Tripura, India: A baseline observation
}

Tapan Majumder ${ }^{1}$, Bitan Sengupta ${ }^{2}$, Subrata Baidya ${ }^{3}$, Himadri Bhattacharya ${ }^{4}$, Anurima Baidya ${ }^{5}$, Apurba Sarkar ${ }^{6}$

${ }^{1}$ Professor and Head, Department of Microbiology, Agartala Government Medical College, Agartala, Tripura, India; ${ }^{2}$ Medical officer, Department of Community Medicine, Agartala Government Medical College, Agartala, Tripura, India; ${ }^{3}$ Professor and Head, Department of Community Medicine, Agartala Government Medical College, Agartala, Tripura, India; ${ }^{4}$ Associate Professor, Department of Community Medicine, Agartala Government Medical College, Agartala, Tripura, India; ${ }^{5} \mathrm{MPH}$ Scholar, Johns Hopkins, Bloomberg School of Public Health, USA; ${ }^{6}$ Research Assistant, Viral Research and Diagnostic Laboratory, Department of Microbiology, Agartala Government Medical College, Agartala, Tripura, India.

\begin{tabular}{|c|c|c|c|c|c|c|c|c|}
\hline Abstract & Introduction & Methodology & Results & Conclusion & References & Citation & & es / Figures \\
\hline \multicolumn{9}{|c|}{ Corresponding Author } \\
\hline \multicolumn{8}{|c|}{$\begin{array}{l}\text { Dr Himadri Bhattacharjya, Associate Professor, Department of Community Medicine, Agartala Government } \\
\text { Medical College, Agartala, Tripura, India, P. O. Kunjavan, Pin: 799006, } \\
\text { E Mail ID: } \underline{\text { hbhattacharjya@rediffmail.com }}\end{array}$} & 回语回 \\
\hline
\end{tabular}

\section{Citation}

Majumder T, Sengupta B, Baidya S, Bhattacharya, Baidya A, Sarkar A. Sero-prevalence of SARS CoV-2 specific antibody among general population of Tripura, India: A baseline observation. Indian J Comm Health. 2021;33(2):260265.https://doi.org/10.47203/IJCH.2021.v33i02.007

Source of Funding: National Health Mission and supported by the Government of Tripura, India.

Conflict of Interest: None declared

\section{Article Cycle}

Received: 01/03/2021; Revision: 18/04/2021; Accepted: 05/05/2021; Published: 30/06/2021

This work is licensed under a Creative Commons Attribution 4.0 International License.

\section{Abstract}

Background: Spectrum of COVID-19 disease ranges from asymptomatic or mild symptomatic to life threatening cases. Population based sero-epidemiological studies are useful for assessing the magnitude of COVID-19 infection in a geographic area and it is helpful for planning control measures. Objectives: To estimate the sero-prevalence of SARS CoV-2 antibody in the general population of Tripura and to study the factors associated with it. Methodology: This community based crosssectional study was conducted from $15^{\text {th }}$ October to $14^{\text {th }}$ November 2020 among 4800 subjects selected from the whole state of Tripura, India by probability proportionate to size sampling technique using 30 clusters. Electrochemiluminescence (eCLIA) based assay was used to test the serum samples for SARS-CoV-2 specific antibody. Data entry and analysis was performed using SPSS-25 for windows and sero-prevalence was expressed in percentages. Binary logistic regression model was used for predicting sero-positivity by including the significant factors associated with SARS-CoV-2 infection as found out by univariate analysis. Result: Sero-prevalence of SARS-CoV-2 antibody was found to be $34 \%$ among the general population of Tripura and it varied from $42.4 \%$ to $19.7 \%$ across different districts. Logistic regression model has identified, urban residency (OR: 1.21, 95\% Cl: 1.03-1.42), ethnic community (OR: $0.55,95 \% \mathrm{Cl}: 0.48-0.64$ ) and literacy (OR: $1.41,95 \% \mathrm{Cl}: 1.13-1.77$ ) as the independent risk factors for SARS-CoV-2 sero-positivity $(p<0.05)$. Conclusion: Approximately one out of three residents of Tripura has already acquired the novel SARS CoV-2 infection. As the threshold required for achieving herd immunity against COVID-19 is not yet known, control measures need to be continued for preventing further spread of disease in the community.

\section{Keywords}

COVID-19, Antibody, Tripura, India.

\section{Introduction}

In 2019 a novel Coronavirus named Severe Acute Respiratory Syndrome Corona virus-2 (SARS-CoV-2) was identified, which first appeared in Wuhan province of China, causing a disease named as COVID-19.(1) Since then the disease has emerged as a pandemic and spread to more than 200 countries and till $15^{\text {th }}$ November of 2020 over 53.7 million cases and 1.3 million deaths have been reported globally.(2) The true proportion of asymptomatic or pre-symptomatic COVID-19 patients varies from region to region.(3) As per data available in the Viral Research and Diagnostic Laboratory (VRDL) located at Agartala Government Medical College, in Tripura, out of all the 
subjects tested for COVID-19 (Including RT-PCR and Rapid

Antigen method) only $7 \%$ were symptomatic. This indicates iceberg nature of this disease. Facility-based surveillance efforts are likely to miss mild and asymptomatic cases which can be estimated only by community based serological surveillance.(4) The World Health Organization (WHO) has recommended population-based sero-epidemiological studies to generate information on the magnitude of COVID-19 infection that can be used to design different control measures.(5) WHO has advised many techniques to recruit subjects for such sero-epidemiological investigation and among them one is multi indicator cluster survey (MICS).(6) In 1980s, WHO developed the Expanded Program on Immunization (EPI) survey methodology, also known as 30 cluster sampling technique and because of its simplicity in application it has been extended to other health surveys with different aims. $(7,8)$

The proportion of people who need to be immune in order to achieve herd immunity varies with each disease. Herd immunity against measles requires about $95 \%$ of a population to be vaccinated. For polio, the threshold is about $80 \%$.

Despite Tripura being a small state in the North-Eastern region of India, it has reported second highest covid-19 cases among all the North-Eastern states after Assam.(9) As of $15^{\text {th }}$ November 2020, total 31959 cases of COVID-19 including 361 deaths due to this disease were reported from Tripura.(10)To contain further spread of COVID-19 in the state, various public health measures are in force. Existing surveillance system screens the symptomatic cases and their contacts, but there remains the possibility of missing out the asymptomatic cases, which may form ice-berg. In this juncture, sero-surveillance for detecting antibody against COVID-19 may be a useful tool to bridge the gap. Information regarding magnitude of COVID-19 infection and its associated factors may be helpful for the state health authority in planning appropriate control measures.

\section{Aim\& Objective}

To estimate the sero-prevalence for SARS CoV-2 antibody and to study the factors associated with it in the general population of Tripura.

\section{Material \& Methods}

Study Type: It was a community based cross-sectional study. Study Population: General population of Tripura. Study Area: Whole state of Tripura. Study Duration: From $15^{\text {th }}$ October to $14^{\text {th }}$ November 2020, Inclusion Criteria: Participants from all age groups. Sample Size calculation: First nationwide survey conducted by Indian Council of Medical Research (ICMR) during the month of May 2020, has found the seroprevalence of SARS-CoV-2 antibody as $0.73 \%$.(11) For determining the minimum sample size requirement for this study, the formula for calculating sample size for prevalence studies using proportion i.e. $N=\left(Z^{2}{ }_{\alpha} \times p \times q\right) \div$ $\mathrm{t}^{2}$ was used.(12) Here, $\mathrm{N}$ is sample size. $\mathrm{Z}$ is the standard normal deviate. $\alpha$ is the level of significance, which is considered as $5 \%$ and value of $Z_{\alpha}$ is 1.96 . $P$ is the present sero-positivity rate, which is considered as $1 \%$ at present, presuming the fact that it would be higher than the prevalence found out by ICMR study which was conducted few months earlier.(11) $t$ ' ' is relative precision, which is taken as $40 \%$ and a design effect of 2 was also considered. Thus minimum sample size requirement for this study was calculated to be 4752 subjects (Rounded to 4800).

Sampling technique: Probability proportionate to size sampling using 30 clusters was followed to select the subjects for this study. Initially a sampling frame consisting of names and populations of all the villages and municipal wards of whole Tripura state was prepared based upon 2011 census data. A cluster was defined as a village or a municipal ward. Cumulative population of all these habitations was also noted down in this frame. Total population of Tripura state was $36,73,917$. Sampling interval was determined by dividing the total population with 30 , the number of clusters to be included in this study. It was found out to be $1,22,464$. A five digit random number 81485 was chosen from the random number table. In the next step, 30 clusters were identified from the sampling frame using this random number and sampling interval following probability proportionate to size sampling procedure.

Working Definitions: Subjects residing in villages as rural and subjects living in municipal areas were considered as urban subjects. Subjects who did not have formal schooling were considered illiterate. Literacy of any level up to standard V as primary, up to standard XII as secondary and beyond that including vocational courses as graduate and above.

Strategy for data collection: Each of these selected clusters was divided into four zones and 40 households were consecutively selected from every zone. One individual was chosen from each of these selected households by simple random sampling. By this process 160 individuals were chosen from each identified clusters. There were 8 districts in Tripura. All the Chief Medical Officers (CMO) and other stake holders of the districts including the District Surveillance Officers (DSO) for COVID-19 were sensitized regarding this study through video conferencing from the state headquarter. District level teams were framed consisting of one Microbiologist and an Epidemiologist or Surveillance Medical Officer. For collection of blood sample and conducting interview field survey teams were constituted throughout the state. Each such team comprised of one ANM or phlebotomist, one panchayet or municipal worker and an Accredited Social Health Activist (ASHA) or a Community Health Officer (CHO). For this survey district level teams were trained at the state headquarter followed by training of the field 
survey teams in a cascade manner on the respective survey sites. All the trainings were supervised by the PI and other resource persons. Logistics and consumables were supplied from the state headquarter. Transportation was arranged by the CMOs.

Selected households were visited by the field survey teams and informed written consent for participation in this study was sought from the head of the families. Exclusion Criteria: Thirteen active COVID-19 cases, 06 infants, one mentally ill person and 07 persons refused to participate in this study were excluded from the sample. To compensate these exclusions, equal numbers of individuals from the neighbouring households of the same clusters were recruited following same method.

Consent: After obtaining written informed consent, the study subjects were interviewed confidentially and information were noted in a pretested interview schedule which contained questions regarding socio-demographic, health and present study related questions. After interviewing, $3 \mathrm{ml}$ of venous blood sample was collected in plain vacutainers from the participants following standard aseptic and lab procedure. Blood filled vacutainers were allowed to stand in the rack for at least half an hour for clotting and then transferred to cold boxes maintaining 20-80C temperature and later on transported to the ICMR designated Viral Research and Diagnostic Laboratory (VRDL), situated at the Department of Microbiology, Agartala Govt. Medical College for analysis. Serum was separated from the samples and examined for the presence of SARS-CoV-2-specific antibody using Electro-chemiluminescence (eCLIA) based assay approved by ICMR.The instrument, 'Cobas e 411 analyzer', model no:741-0050, manufactured by Roche on 2018-04-04 was used for this purpose. Manufacturer of the machine has declared the sensitivity of this test as $85.3 \%$ if serum sample is tested within 7-13 days and $99.5 \%$ if tested after 14 days of acquiring the infection. The specificity declared was $99.8 \%$.

Data Analysis and software: Data entry and analysis were performed with computer by using SPSS-25 for windows.(13) Quantitative data were summarized in terms of means and standard deviation and proportions were used for the qualitative data. Sub-group analysis was done to estimate the sero-prevalence in each cluster and in groups differentiated by age, geography, profession, residence etc. Chi-square test was applied to test the significance of difference between different sub-groups. To study the effect of significant predictor variables upon SARS-CoV-2 infection, binary logistic regression model was applied and a $\mathrm{p}$ value $<0.05$ was considered statistically significant.

This survey was permitted and supported by the Government of Tripura and was also approved by the Ethical Approval: Institutional Ethics Committee of Agartala Government Medical College. Participant's confidentiality was maintained throughout the study.

\section{Results}

Total 4800 participants were approached for participation in this study in the study from the selected 30 clusters and samples were collected from all of them. Among the 30 clusters, 8 were located in urban and the remaining 22 in the rural areas. Out of 4800 blood samples collected, 26 were either haemolysed or not eligible for detection of SARS-CoV-2-specific antibody. Thus finally analysis was limited to the lab result of 4774 samples.

Mean age of the participants was $39.8 \pm 13.85$ years and majority (84.6\%) of the participants was aged between 19 to 59 years. Majority of the participants were male (55.1\%) and $81.6 \%$ belonged to rural areas. About $5 \%$ of the participants were suffering from some form of chronic diseases or co-morbid conditions. Among all, 29 participants $(0.6 \%)$ gave history of getting diagnosed as COVID-19 positive and also got recovered from the same prior to the study. Another 10 participants (0.2\%) gave history of close contact with confirmed COVID-19 patients. Socio-demographic profile of the study participants is shown in (Table 1).

Among 4774 serum samples tested, 1623 (34\%) were found to be positive for SARS-CoV-2-specific antibody. Among 8 districts of Tripura state, Sepahijala district had the highest sero-positivity rate $(42.4 \%)$, followed by Gomati district (41.4\%) and West Tripura district (41.1\%). District wise sero-positivity rate for SARS CoV-2 antibody is shown in (Table 2).

SARS CoV-2 antibody was detected in the serum samples received from $41.4 \%$ of the urban and $31.4 \%$ of the rural residents. Sero-positivity rate was $34.5 \%$ in female and $33.6 \%$ in male subjects. About $38.5 \%$ of the study subjects with co-morbid conditions had SARS CoV-2 antibody in their serum. In bivariate analysis, residence, socioeconomic status, literacy and community of the study subjects were found to have significant associations with sero-positivity rate of SARS CoV-2 specific antibody. (Table 3)

Binary logistic regression model was run to study effect of significant predictor variables upon sero-positivity rate for SARS CoV-2 specific antibody. Urban residents had $21 \%$ higher chance of acquiring SARS CoV-2 specific antibody than the rural (OR: 1.21, 95\% Cl: 1.03-1.42, P <0.05). Similarly literate subjects had $53 \%$ higher chance of acquiring SARS CoV-2 specific antibody than the illiterates (OR: 1.53, 95\% Cl: 1.21-1.92, $\mathrm{P}<0.05$ ) and both were significant. Ethnic origin of the study subjects showed significant protective effect against SARS CoV-2 infection. (OR: 0.54, 95\% Cl: 0.47-0.63, P <0.05). (Table 4)

\section{Discussion}

In the present survey, study subjects were recruited from throughout the state of Tripura including both rural urban, ethnic and non-ethnic population covering all age groups. This study has revealed that $34 \%$ of the population of Tripura got exposed to the novel corona virus prior to this 
survey and has developed SARS CoV-2 specific antibody. Sero-prevalence of SARS CoV-2 specific antibody varied from $42.4 \%$ to $19.7 \%$ across different districts of the state. As of now, ICMR has conducted two rounds of nationwide sero-survey for COVID-19 antibody covering different districts of India and detected the sero-prevalence as $0.73 \%$ and $7.1 \%$ in the first and second survey respectively. $(11,14)$ Findings of both the studies were much lower than the present study. This may be due to the fact that during late phage of lockdown, huge number of COVID-1`9 positive migrants have returned back to their home state of Tripura from different parts of the country and introduced large scale infection in this community. This was evident from the daily COVID test report of the returnees.

Besides ICMR, many other states had also conducted serological surveys for SARS CoV-2 antibody and their results were also higher than the ICMR study. Seroprevalence of SARS CoV-2 antibody varied from $8 \%$ in Indore to $51 \%$ in Pune.(15) Two rounds of serological survey in Delhi revealed the sero-prevalence of $23 \%$ and $29 \%$ respectively.(16) In the present study, significantly higher sero-prevalence of SARS CoV-2 antibody was detected in the samples collected from the urban areas $(41 \%)$ as compared against the rural areas (31\%). This observation is at par with the findings of ICMR study, where higher sero-prevalence was reported from the urban regions. $(11,14)$ This difference may be due to the higher population density in urban areas with greater chances of social mixing favouring transmission of COVID19 infection. Sepahijala district showed highest seropositivity rate. It may be due to the fact that huge number of subjects from this particular district were working outside the state and returned home during late phage of lockdown after acquiring COVID-19 infection from work place, as diagnosed at their entry.

Present study has reported higher sero-prevalence of SARS CoV-2 antibody among females (34\%) than the males (33\%) in Tripura, though it was not statistically significant. This result is consistent with the findings of serological surveys conducted in Delhi and Mumbai, where females showed higher sero-prevalence.(16) In the present study, higher sero-prevalence was observed among the productive age group subjects (18-59 yr) than older (>60 $\mathrm{yr})$ and children $(<18 \mathrm{yr})$ though statistically it was not significant. This observation is at par with the result of COVID-19 sero-survey conducted in Pune, where younger age group subjects had higher sero-prevalence.(17) On the contrary, second round of serological survey conducted in Delhi reported higher sero-prevalence among children than adults. (17)

In the present study, significantly higher chance of acquiring SARS CoV-2 antibody was observed among the literate subjects. This may be due to the fact that literate subjects were more mobile and had more interactions with other persons. This may be due to the nature of their job. Ethnic population of the state showed lesser SARS CoV-2 sero-positivity rate and it may be due to the fact that such population is predominantly settled in hilly areas with very thin population density and lesser contact with the incoming migrant population.

Sero-surveys provide estimate of the total number of infections in a geographic area. Based up on the present sero-prevalence of $34 \%$ and 29,800 reported number of COVID-19 cases in Tripura till 31st October 2020 (Diagnosed by RT-PCR and Rapid Antigen Test) and considering the total population of Tripura as 36,73,917 (Census-2011) it may be postulated that for every confirmed case of COVID-19, there might be 42 infections in Tripura state.

\section{Conclusion}

This sero-survey indicates that nearly one third of the population of Tripura has got infected with the novel SARS CoV-2 virus. Based up on the present sero-prevalence of $34 \%$ and 29,800 reported number of COVID-19 cases in Tripura till 31st October 2020 (Diagnosed by RT-PCR and Rapid Antigen Test) and considering the total population of Tripura as 36,73,917,(Census-2011) it may be presumed that for every confirmed case of COVID-19, there might be 42 in apparent infections in Tripura state. By convention, at least $50-90 \%$ subjects in a given community should develop antibody in order to show herd immunity against an infectious disease. This is proven in case of Measles and Poliomyelitis. But the proportion of population requiring antibody to show herd immunity against COVID-19 is yet to be ascertained. Moreover, achievement of herd immunity through natural infection is not desirable due to huge number of morbidities and mortalities.

\section{Recommendation}

Hence public health measures need to be continued for controlling further spread of the disease in this community.

\section{Relevance of the study}

This study will serve as baseline data for a follow up study to assess the antibody titre and its protective efficacy among the sero-positives with the passage of time. Result of this study may also guide the health authorities in calculating vaccine requirement for the state.

\section{Authors Contribution}

All authors contributed equally.

\section{Acknowledgement}

Authors acknowledge National Health Mission for funding and Govt. of Tripura for supporting this study.

\section{References}

1. Zhu N, Zhang D, Wang W, Li X, Yang B, Song J et al. A novel coronavirus from patients with pneumonia in China, 2019. N. Engl. J. Med. 2020; 382: 727-33. . Available from: https://doi.org/10.1056/nejmoa2001017 [Accessed on 25.06.2021]. 
2. World Health Organization. COVID-19 Weekly Epidemiological Update 17 November 2020. Geneva: WHO; 2020. [Internet]. Available from: https://www.who.int/publications/m/item/weekly-epidemiologicalupdate---17-november-2020 [Accessed on 25.06.2021].

3. Heneghan C, Brassey J, Jefferson T. COVID-19: What proportion are asymptomatic? The Centre for Evidence-Based Medicine, April 6, 2020; Available from: https://www.cebm.net/covid-19/covid-19-whatproportion-are-asymptomatic/ [Accessed on 25.06.2021].

4. Kumar MS, Bhatnagar T, Manickam P, Kumar VS, Rade K, Shah N et al. National sero-surveillance to monitor the trend of SARS-CoV-2 infection transmission in India: Protocol for community-based surveillance. Indian J Med Res 2020;151:419-23.

5. World Health Organization. Coordinated global research roadmap: 2019 novel coronavirus; March 2020. Geneva: WHO; 2020

6. World Health Organization. Population-based age stratified seroepidemiological investigation protocol for COVID-19 virus infection. Available from: https://www.who.int/publicationsdetail/populationbasedage- stratified sero-epidemiological investigation protocol for COVID-19 virus infection..

7. Henderson RH, Sundaresan T. Cluster sampling to assess immunization coverage: a review of experience with a simplified sampling method. Bulletin of the World Health Organization 1982; 60(2): 253-60.

8. Bennett $\mathrm{S}$, Woods $\mathrm{T}$, Liyanage WM, Smith DL. A simplified general method for cluster-sample surveys of health in developing countries. World health statistics quarterly 1991; 44: 98-106.

9. Ministry of health and family welfare, India. COVID-19 state wise status. November 2020. New Delhi: MOHFW; 2020. Available from: https://www.mohfw.gov.in/ [Accessed on 25.06.2021].

10. Government of Tripura. COVID-19 portal. Available from: https://covid19.tripura.gov.in/ [Accessed on 25.06.2021].
[SARS CoV-2...] | Majumder T et al

11. Murhekar MV, Bhatnagar T, Selvaraju S, Rade K, Saravanakumar V, Thangaraj JW et al. Prevalence of SARS-CoV-2 infection in India: Findings from the national sero-survey, May-June 2020. Indian J Med Res 2020; 152:48-60.

12. Peacock JL, peacock PJ. Oxford handbook of medical statistics, 1st Edition, oxford university press, Oxford. Chapter one: 60-1.

13. IBM Corp. Released 2017. IBM SPSS Statistics for Windows, Version 25.0. Armonk, NY: IBM Corp.

14. Kaunain SM. Just 6.6\% exposed to COVID till August: New sero-survey. The Indian express 2020 Sep 30. Available from: https://indianexpress.com/article/india/india-covid-19-august-serosurvey-6637821/. [Accessed on 25.06.2021]

15. Press trust of India. How much has COVID-19 spread in India? What recent serosurvey tell us. The week 2020 Sep 4. [Internet]. Available from: https://www.theweek.in/news/india/2020/09/04/how-muchhas-covid-19-spread-india-what-recent-serosurveys-tell-us.html .[Accessed on 25.06.2021]

16. Goswami S, Dey A. $29 \%$ of Delhi has antibodies for Covid-19: Second sero-survey. Hindustan Times 2020 Aug 20. [Internet]. Available from: https://www.hindustantimes.com/india-news/29-of-delhi-hasantibodies-for-covid-19-second-sero-survey/storyJE4rKi7IMDYaOgAacWoCVK.html .[Accessed on 25.06.2021]

17. Rukmini S. 5 things that serosurvey can tell us about the true spread of COVID. India today 2020 Aug 26. Available from: https://www.indiatoday.in/diu/story/5-things-that-sero-surveys-cantell-us-about-true-spread-of-covid-1715465-2020-08-26 [Accessed on 25.06.2021]

\section{Tables}

TABLE 1: SOCIO-DEMOGRAPHIC PROFILE OF THE STUDY SUBJECTS ( $\mathrm{N}=4774$ )

\begin{tabular}{|c|c|c|c|}
\hline \multicolumn{2}{|c|}{ Variables } & \multicolumn{2}{|c|}{ Study subjects } \\
\hline & & Number & Percentage \\
\hline \multirow[t]{2}{*}{ Residence } & Rural & 3896 & 81.6 \\
\hline & Urban & 878 & 18.4 \\
\hline \multirow[t]{3}{*}{ Age } & $<18$ year & 184 & 3.9 \\
\hline & 18-59 year & 4095 & 85.8 \\
\hline & $\geq 60$ year & 495 & 10.4 \\
\hline \multirow[t]{2}{*}{ Sex } & Male & 2634 & 55.2 \\
\hline & Female & 2140 & 44.8 \\
\hline \multirow[t]{4}{*}{ Community } & General & 1460 & 30.6 \\
\hline & Scheduled caste & 907 & 19.0 \\
\hline & Scheduled tribe & 1476 & 30.9 \\
\hline & Other Backward Community & 931 & 19.5 \\
\hline \multirow[t]{4}{*}{ Literacy } & Illiterate & 455 & 9.5 \\
\hline & Primary educated & 2497 & 52.3 \\
\hline & Secondary educated & 1335 & 28 \\
\hline & Graduate and above & 487 & 10.2 \\
\hline \multirow[t]{2}{*}{ Socio-economic status } & Above Poverty Line & 2288 & 47.9 \\
\hline & Bellow Poverty Line & 2486 & 52.1 \\
\hline \multirow[t]{5}{*}{ Co-morbidity } & Hypertensive & 114 & 2.4 \\
\hline & Diabetic & 86 & 1.8 \\
\hline & Multiple diseases & 12 & 0.2 \\
\hline & Others $\#$ & 22 & 0.5 \\
\hline & No co-morbidity & 4540 & 95.1 \\
\hline \multirow[t]{2}{*}{ COVID-19 disease } & Suffered & 29 & 0.6 \\
\hline & Not suffered & 4747 & 99.4 \\
\hline \multirow{2}{*}{$\begin{array}{l}\text { History of contact with any COVID-19 } \\
\text { case }\end{array}$} & Present & 10 & 0.2 \\
\hline & Absent & 4766 & 99.8 \\
\hline
\end{tabular}




\section{TABLE 2: DISTRICT WISE SERO-POSITIVITY OF SARS COV-2 ANTIBODYIN TRIPURA}

\begin{tabular}{|lcccc|}
\multicolumn{1}{c}{ Districts } & No of clusters & $\begin{array}{c}\text { Subjects } \\
\mathrm{n}(\%)\end{array}$ & $\begin{array}{c}\text { Sero-positivity } \\
\mathrm{n}(\%)\end{array}$ & $\begin{array}{c}\text { Sero-positivity } \\
\%(95 \% \mathrm{CI})\end{array}$ \\
\hline West Tripura & 8 & $1271(26.6)$ & $522(32.2)$ & $41.1(38.3-43.8)$ \\
\hline Sipahijala & 3 & $479(10.0)$ & $203(12.5)$ & $42.4(37.9-46.9)$ \\
\hline Gomati & 3 & $478(10.0)$ & $198(12.2)$ & $41.4(37.0-46.0)$ \\
\hline South Tripura & 4 & $636(13.4)$ & $125(7.7)$ & $19.7(16.6-23.0)$ \\
\hline Khowai & 3 & $477(10.0)$ & $190(11.7)$ & $39.8(35.4-44.4)$ \\
\hline Dhalai & 3 & $478(10.0)$ & $125(7.7)$ & $26.2(22.3-30.3)$ \\
\hline Unokoti & 2 & $318(6.6)$ & $115(7.1)$ & $36.2(30.9-41.7)$ \\
\hline North Tripura & 4 & $637(13.4)$ & $145(8.9)$ & $22.8(19.6-26.2)$ \\
\hline Total & 30 & 4774 & 1623 & $34.0(32.7-35.4)$ \\
\hline
\end{tabular}

\begin{tabular}{|c|c|c|c|c|}
\hline \multirow[t]{2}{*}{ Variables } & \multirow[t]{2}{*}{ Subgroups } & \multicolumn{2}{|c|}{ Serology } & \multirow[t]{2}{*}{$p$-value } \\
\hline & & Positive & Negative & \\
\hline \multirow{2}{*}{ Residence } & Rural & $1255(32.2)$ & $2641(67.8)$ & \multirow[t]{2}{*}{0.000} \\
\hline & Urban & 368 (41.9) & $510(58.1)$ & \\
\hline \multirow{3}{*}{ Age } & $<18 \mathrm{yr}$ & $53(28.8)$ & $131(71.2)$ & \multirow[t]{3}{*}{0.147} \\
\hline & $18-59 \mathrm{yr}$ & $1413(34.5)$ & $2682(65.5)$ & \\
\hline & $\geq 60 \mathrm{yr}$ & $157(31.7)$ & $338(68.3)$ & \\
\hline \multirow{2}{*}{ Sex } & Male & $884(33.6)$ & $1750(66.4)$ & \multirow[t]{2}{*}{0.481} \\
\hline & Female & $739(34.5)$ & $1401(65.5)$ & \\
\hline \multirow{4}{*}{ Community } & General & $546(37.4)$ & $914(62.6)$ & \multirow[t]{4}{*}{0.000} \\
\hline & Scheduled caste & $393(43.3)$ & $514(56.7)$ & \\
\hline & Scheduled tribe & $362(24.5)$ & $1114(75.5)$ & \\
\hline & Other Backward Community & $322(34.6)$ & $609(65.4)$ & \\
\hline \multirow{4}{*}{ Literacy } & Illiterate\# & $121(26.6)$ & $334(73.4)$ & \multirow[t]{4}{*}{0.001} \\
\hline & Primary & $842(33.7)$ & $1655(66.3)$ & \\
\hline & Secondary & $484(38.87)$ & $761(61.13)$ & \\
\hline & Graduate & $176(36.1)$ & $311(63.9)$ & \\
\hline \multirow{2}{*}{ Economic status } & APL & $814(35.6)$ & $1474(64.4)$ & \multirow[t]{2}{*}{0.027} \\
\hline & BPL & 809 (32.5) & $1677(67.5)$ & \\
\hline \multirow{2}{*}{ Co-morbidity } & Present & $90(38.5)$ & $144(61.5)$ & \multirow[t]{2}{*}{0.139} \\
\hline & Absent & $1533(33.8)$ & 3007 (66.2) & \\
\hline
\end{tabular}

\section{TABLE 4: RESULT OF BINARY LOGISTIC REGRESSION ANALYSIS}

\begin{tabular}{|c|c|c|c|}
\hline & & Adjusted OR $(95 \% \mathrm{Cl})$ & p-value \\
\hline \multirow[t]{2}{*}{ Age } & $<18 \mathrm{yr}$ & 1 & \\
\hline & $\geq 18 \mathrm{yr}$ & $1.16(0.79-1.70)$ & 0.434 \\
\hline \multirow[t]{2}{*}{ Residence } & Rural & 1 & \multirow[t]{2}{*}{0.018} \\
\hline & Urban & $1.21(1.03-1.42)$ & \\
\hline \multirow[t]{2}{*}{ Sex } & Male & 1 & \multirow[t]{2}{*}{0.805} \\
\hline & Female & $1.01(0.89-1.14)$ & \\
\hline \multirow[t]{2}{*}{ Economic status } & BPL & 1 & \multirow[t]{2}{*}{0.195} \\
\hline & APL & $1.08(0.96-1.22)$ & \\
\hline \multirow[t]{2}{*}{ Ethnicity } & Non-ethnic & 1 & \multirow[t]{2}{*}{0.000} \\
\hline & Ethnic & $0.55(0.48-0.64)$ & \\
\hline \multirow[t]{2}{*}{ Co-morbidity } & Absent & 1 & \multirow[t]{2}{*}{0.673} \\
\hline & Present & $1.06(0.80-1.40)$ & \\
\hline \multirow[t]{2}{*}{ Literacy } & Illiterate & 1 & \multirow[t]{2}{*}{0.002} \\
\hline & Literate & $1.41(1.13-1.77)$ & \\
\hline
\end{tabular}

